\title{
On the argumenthood of optional PPs with Italian motion verbs
}

\author{
Giulia Cappelli ${ }^{1}$, Pier Marco Bertinetto ${ }^{1}$, Alessandro Lenci ${ }^{2}$ \\ ${ }^{1}$ Scuola Normale Superiore, Italy \\ ${ }^{2}$ University of Pisa, Italy \\ https://doi.org/10.36505/ExLing-2019/10/0011/000373
}

\begin{abstract}
In this study, we investigated the argumenthood of locative PPs occurring with motion verbs in Italian, by means of a behavioral experiment based on the traditional optionality test for argumenthood. Previous research relied on linguists' intuitions or corpus frequencies, and to our knowledge no published research on motion verbs in Italian has employed a behavioral experiment yet. Consistently with recent literature, we show that the optional PPs occurring with each motion verb have different argumenthood scores on a gradient scale depending on the interaction between their Aktionsart and morphosyntactic class. We observed that achievements occur with adjuncts, activities with in-between constituents, accomplishments either with arguments or with adjuncts depending on their auxiliary in compound tenses.
\end{abstract}

Key words: argumenthood, acceptability judgments, motion verbs, Italian, syntax

\section{Introduction}

In this paper, we are interested in the argumenthood of locative PPs occurring with motion verbs in Italian. Much has been written about it, the fragile consensus being that Goals are arguments of directed-motion verbs and other PPs are adjuncts; however, it is still common practice to rely on individual intuitions and on a binary argument/adjunct distinction.

Following Cennamo \& Lenci (2018), we aim to show that differences in the argumenthood of optional PPs with motion verbs stem from the interaction between the Aktionsart of verbs and their morphosyntactic class. Here we argue for a gradient argument/adjunct distinction by means of a behavioral experiment, using PP optionality as a test for argumenthood.

\section{Experimental setting}

\section{Materials and methods}

Our experiment targeted 44 unique Italian motion verbs. We classified each verb according to its Aktionsart and verb class (Folli 2001, Cennamo \& Lenci 2018), the latter based on auxiliary selection (see Table 1).

Some Class 2 activity verbs can be reclassified into accomplishments by changing their auxiliary in compound tenses from 'have' to 'be'. Under the optionality test, a given constituent is an argument if its omission results in an

ExLing 2019: Proceedings of 10 $10^{\text {th }}$ International Conference of Experimental Linguistics, 25-27 September 2019, Lisbon, Portugal 


\section{G. Cappelli, P.M. Bertinetto, A. Lenci}

ungrammatical sentence, while it is an adjunct if the sentence remains grammatically correct without it. Thus, we tested the argumenthood of the PPs they occur with by using as stimuli 48 (given that 4 verbs out of 44 can have both auxiliaries) Italian sentences only consisting of a subject and a motion verb in the present perfect tense.

Table 1. Classification of motion verbs in Italian.

\begin{tabular}{|l|l|l|l|}
\hline \hline & Class $1_{\mathrm{BE}}$ & Class 2 $\mathrm{BE} / \mathrm{HAVE}$ & Class $3_{\mathrm{HAVE}}$ \\
\hline achievement & $\begin{array}{l}\text { arrivare } \\
\text { 'to arrive' }\end{array}$ & $\begin{array}{l}\text { decollare } \\
\text { 'to take off }\end{array}$ & - \\
\hline accomplishment & $\begin{array}{l}\text { cadere } \\
\text { 'to fall' }\end{array}$ & $\begin{array}{l}\text { correre } \\
\text { 'to run' }\end{array}$ & - \\
\hline activity & - & $\begin{array}{l}\text { correre } \\
\text { 'to ruVE }\end{array}$ & $\begin{array}{l}\text { camminare } \\
\text { 'to walk' }\end{array}$ \\
\hline \hline
\end{tabular}

We recruited 40 native speakers with no training in linguistics, giving each of them $5 €$ as compensation. Each participant was presented with a random sample of sentences, selected so that each sentence received acceptability judgments (on a 7-point Likert scale) from 25 participants. Applying the optionality test, low acceptability scores point to the argument-like status of the optional PP, while high scores point to adjuncthood.

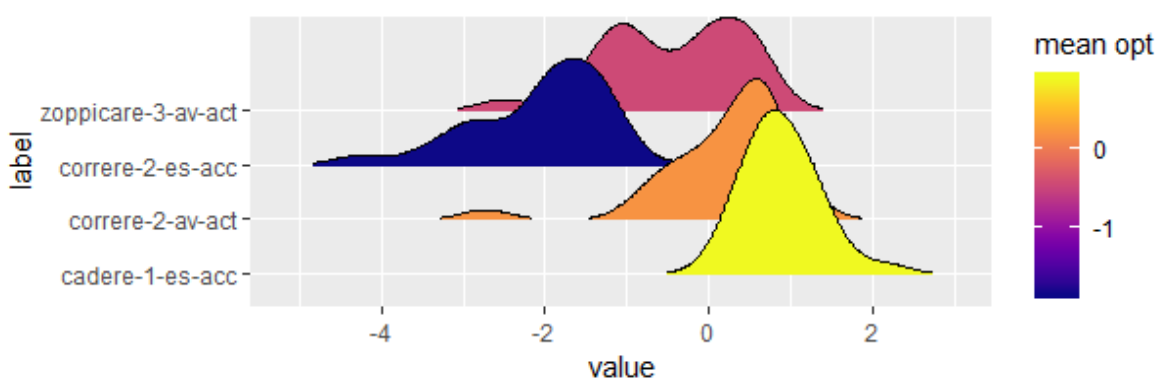

Figure 1. Density plots with z-normalized optionality scores for the verbs zoppicare 'to limp', correre 'to run', cadere 'to fall down'.

Following Kim et al. (2018), we accounted for individual differences in the use of the Likert scale by z-transforming the 25 judgments for each verb. The statistical analysis was carried out in R (R Core Team 2019), and density plots (as in Figure 1 above) were created using the $\mathrm{R}$ packages ggplot2 (Wickham 2016), ggridges (Wilke 2018) and viridis (Garnier 2018).

\section{Results}

Based on z-transformed optionality scores, there is a clear tendency for motionverb sentences without a PP to be fully acceptable when the verbs are 
achievements $(\mathrm{Mdn}=.55)$ and Class 1 accomplishments $(\mathrm{Mdn}=.48)$, fully unacceptable when the verbs are Class 2 accomplishments ( $\mathrm{Mdn}=-.55)$, halfway acceptable when the verbs are activities $(\mathrm{Mdn}=.09)$. Given that optionality is inversely proportional to argumenthood, we take this to mean that achievements and Class 1 accomplishments occur with adjuncts, Class 2 accomplishments with arguments, and activities with intermediate constituents (what Grimshaw 1990 called "argument-adjuncts"). A Wilcoxon rank-sum test indicated that the PPs occurring with Class 1 accomplishments are significantly more optional than the ones occurring with Class 2 accomplishments (W = 61716, $\mathrm{p}<.001)$. A Welch's Anova test indicated that optionality scores for the three Aktionsarten are significantly different $(\mathrm{F}(2,964.36)=59.03, \mathrm{p}<.001)$. Participants tend to agree more on adjuncthood than on argumenthood, based on the Pearson correlation between average score and between-subject variance $(\mathrm{r}(46)=-.86, \mathrm{p}<.001)$.

\section{Conclusions}

We argue that inherently telic motion verbs (i.e. achievements and Class 1 accomplishments) preferably occur with adjuncts because they have Goals as implicit arguments (Williams 2015) and their other possible PPs are adjunct-like in nature (Nam 2004). By contrast, the presence of a Goal triggers the reclassification of some activities in Class 2 into accomplishments, as shown by their shift from have-selecting inergatives to be-selecting unaccusatives (Sorace 2000 among others). Thus, Class 2 accomplishments occurring without a PP are deemed ungrammatical, because their 'be' auxiliary surfaces precisely to allow for the expression of an overt Goal. Now consider the intermediate status of the PPs occurring with activities. Limited to Class 2 activities, one could argue that some participants judge the PPs as adjuncts because they cannot occur with Goals, while other participants consider them as arguments because they intuitively perceive the possibility of transforming them into accomplishments, and other participants possibly provide intermediate judgments because they access both readings at once (Zubizarreta \& Oh 2007, Rappaport-Hovav \& Levin 2008). However, Class 3 activities cannot be reclassified into accomplishments, yet the argumenthood of PPs occurring with them is intermediate: we argue that this depends on the atelic nature of activities, which causes them to be less polarized than accomplishments and achievements with respect to argumenthood. Finally, we interpret the overall higher agreement on adjuncthood than on argumenthood as proof that motion verbs tend indeed not to select for arguments: thus, participants tend to preferably activate the adjunct reading even when faced with an argumentselecting verb. 


\section{Acknowledgements}

We thank Najoung Kim for prompting this study and for her invaluable advice, and the anonymous reviewers for their sharp critique of our abstract.

\section{References}

Cennamo, M., Lenci, A. 2018. Gradience in Subcategorization? Locative Phrases with Italian Verbs of Motion. Studia Linguistica, 1-29.

Folli, R. 2001. Two strategies to construct Telicity: A comparative analysis of English and Italian. Working Papers in Linguistics, Philology \& Phonetics, 47.

Garnier, S. 2018. viridis: Default Color Maps from 'matplotlib'. R package

version 0.5.1. https://CRAN.R-project.org/package=viridis

Grimshaw, J. 1990. Argument structure. The MIT Press.

Kim, N., Rawlins, K., Van Durme, B., Smolensky, P. 2018. Predicting the Argumenthood of English Prepositional Phrases. Retrieved from http://arxiv.org/abs/1809.07889

Levin, B., Rappaport Hovav, M. 2008. Lexicalized manner and result are in complementary distribution. IATL, 26-27.

Nam, S. 2004. Goal and Source: Their Syntactic and Semantic Asymmetry. Annual Meeting of the Berkeley Linguistics Society, 301.

R Core Team 2019. R: A language and environment for statistical computing. R

Foundation for Statistical Computing, Vienna, Austria. https://www.R-project.org/.

Sorace, A. 2000. Gradients in auxiliary selection with intransitive verbs. Language, 859890.

Vater, H. 1978. On the possibility of distinguishing between complements and adjuncts. Valence, Semantic Case and Grammatical Relations, 1, 21-45.

Wickham, H. 2016. ggplot2: Elegant Graphics for Data Analysis. Springer-Verlag New York.

Wilke, C. O. 2018. ggridges: Ridgeline Plots in 'ggplot2'. R package version

0.5.1. https://CRAN.R-project.org/package=ggridges

Williams, A. 2015. Arguments in Syntax and Semantics.

Zubizarreta, M. L., Oh, E. 2007. On the syntactic composition of manner and motion. The MIT Press. 